\title{
Membrane Reactors for Renewable Fuel Production and Their Environmental Benefits
}

\author{
Sanaa Hafeez ${ }^{1}$, S.M. Al Salem ${ }^{2}$ and Achilleas Constantinou ${ }^{1,3 *}$
}

${ }^{1}$ Division of Chemical \& Petroleum Engineering, School of Engineering, London South Bank University, London SE1 0AA, UK.

${ }^{2}$ Environment \& Life Sciences Research Centre, Kuwait Institute for Scientific Research, P.O. Box: 24885, Safat 13109, Kuwait.

${ }^{3}$ Department of Chemical Engineering, University College London, London WCIE 7JE, UK.

Author for correspondence; Dr A. Constantinou; Email: constaa8@lsbu.ac.uk; Tel: +44(0)20 78157185

\begin{abstract}
In this communication, we discuss various production methods as potential venues targeted towards alternative fuel generation. These will revolve around the Fischer-Tropsch (FT) process, biodiesel and hydrogen generation techniques. The implementation of membrane reactors in the production of fuels will be shown and discussed; and their advantages will be detailed. The main routes of hydrogen production are also detailed, which include autothermal reforming and biological process. This was done to compare the main advantages of various techniques for the production of hydrogen, as it is noted to be the most desired utility fuel that can serve various purposes. The application of membranes also facilitates an increase in the conversion of desired products, whilst shifting the equilibrium of the reaction and reducing undesired by-products. Membrane reactors also overcome immiscibility issues that hinder conventional reactor processes. Membrane reactors are also demonstrated to reduce the difficulty in separating and purifying impurities, as they couple separation and reaction in one process. This shows drastic economic and energy requirement reductions in the amount of wastewater treatment associated with conventional fuel production reactor. Emphasis is also paid to catalytic membranes used for the production of biodiesel, which can also remove glycerol from the product line as an added advantage.
\end{abstract}

Keywords: Counter Current Membrane, Fischer-Tropsch, Hydrogen, Pyrolysis, Transesterification. 


\section{Contents}

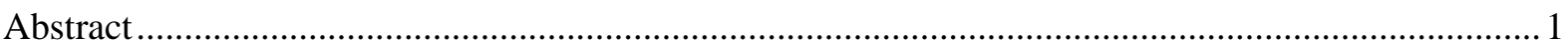

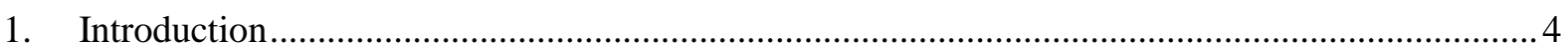

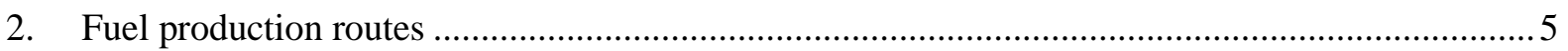

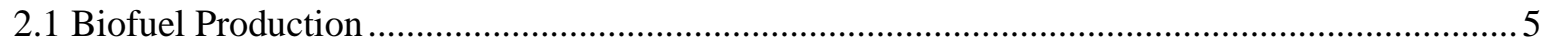

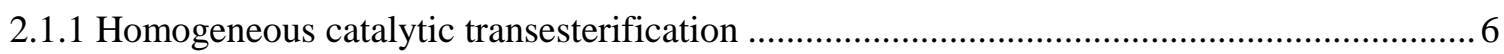

2.1.2 Heterogeneous catalytic transesterification.................................................................. 7

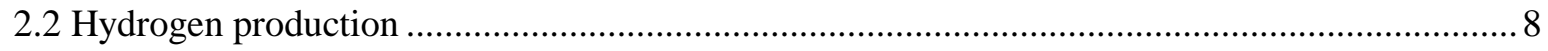

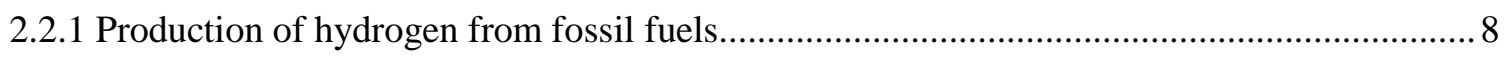

2.2.2 Production of hydrogen from renewable resources ........................................................ 11

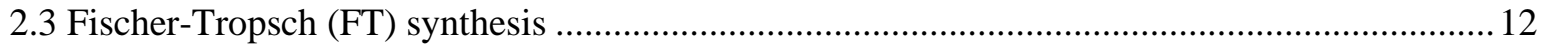

3. Membrane reactors versus conventional systems for environmental applications ...................... 13

4. Membrane reactors for renewable fuel production ................................................................. 14

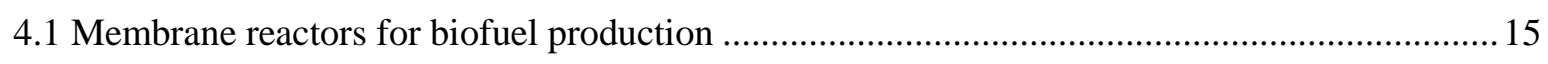

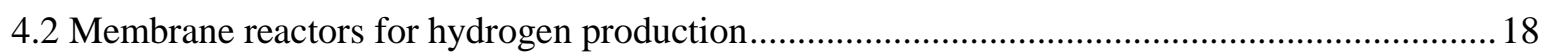

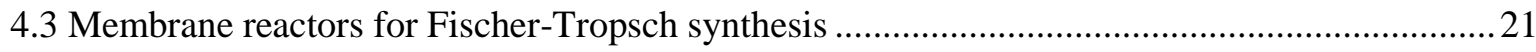

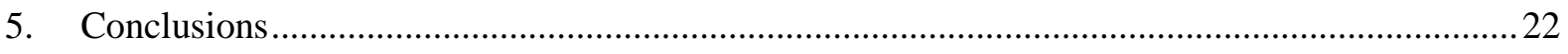

6. Acknowledgments..................................................................... Error! Bookmark not defined.

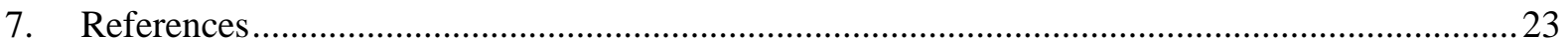




\section{Abbreviations}

$\mathrm{CH}_{4}$;

Methane

$\mathrm{CO}$

Carbon Monoxide

$\mathrm{CO}_{2}$

Carbon Dioxide

FAME;

Fatty Acid Methyl Esters

FT;

Fischer-Tropsch

GHGs;

Greenhouse Gases

$\mathrm{HC}$;

Hydrocarbon

ML-CMR

Monolith Loop Catalytic Membrane Reactor

$\mathrm{Ni}$;

Nickel (Based Catalyst)

$\mathrm{O}_{2}$

Oxygen

PSA;

Pressure Swing Absorption

PVA;

Poly (Vinyl Alcohol)

$\mathrm{Rh}$;

Rhodium (Based Catalyst)

SMR

Steam Methane Reforming

$\mathrm{SO}_{2}$

Sulphur Dioxide

SPVA;

Sulfonated Poly(Vinyl Alcohol)

TCT;

Thermo-Chemical Treatment 


\section{Introduction}

The increase in the global population has led to greater fossil fuel consumption, and as a result, a significant increase of greenhouse gases (GHGs) in the atmosphere. This poses a serious threat to the worldly environment and subsequently impacts climate change. Fossil fuels are the slowest growing source of energy, and their supplies are dwindling daily (Barreto, 2018). The price of fossil fuel resources is also increasing due to their heightened demand. The increasing emissions of carbon dioxide $\left(\mathrm{CO}_{2}\right)$, sulphur dioxide $\left(\mathrm{SO}_{2}\right)$, hydrocarbons $(\mathrm{HCs})$ and volatile hydrocarbons from the burning of fossil fuels leads to significant amount of air pollution and global warming (Shuit et al., 2012). Recent fuel production technologies have focused on utilising renewable resources, in order to, be more sustainable and environmentally friendly. Alternative fuels such as biodiesel and hydrogen, and the products from Fischer-Tropsch (FT) process are now commercially produced to offer a solution towards the aforementioned problems.

Hydrogen is a promising fuel for the environment as its only waste product is water. It can be produced from any primary energy resource and can be used for direct combustion in an internal combustion engine or in a fuel cell (Marbán and Valdés-Solís, 2007). Furthermore, hydrogen is the only carbonfree fuel and has the highest energy content amongst all fuel types. It is also deemed globally as an environmentally benign form of renewable energy as opposed to conventional fossil fuels. Moreover, hydrogen can be used for domestic purposes because it has the potential to be transported by typical means, and for it to be fed to stationary fuel cells, it can be stored as a solid hydride, compressed gas or cryogenic liquid (Nikolaidis and Poullikkas, 2017). Hydrogen fuel can be produced from fossil fuels by using methods such as steam reforming, partial oxidation and autothermal reforming. It can also be produced from non-renewable resources such as thermos-chemical treatment (TCT) and biological processes, and water splitting methods.

Biodiesel as a source of energy has received a lot of attention due to the fact that it is renewable, biodegradable, and can deliver a better quality of exhaust gas emissions (Lu et al., 2007; Wang et al., 2009). Biodiesel is a mixture of monoalkyl esters of long-chain fatty acids derived from renewable lipid feedstocks, for example vegetable oils and animal fats. Biodiesel has demonstrated superiority over conventional diesel fuel, due to its higher combustion efficiency, cleaner emissions, higher cetane number, biodegradability, higher flash point and better lubrication (Shuit et al., 2012). A variety of methods such as dilution, microemulsion, pyrolysis and transesterification have been utilised to reduce the viscosity of vegetable oil so that it is suitable for use as a fuel. Transesterification is the most common route used to produce biodiesel and the reactions include homogeneous catalysed transesterification, heterogeneous catalysed transesterification, enzymatic catalysed transesterification and supercritical technology. 
Membrane reactors have successfully been employed to intensify the renewable fuel production processes (Gutiérrez-Antonio et al., 2018; Pal et al., 2018; Tian et al., 2018). One of the most prominent advantages of the membrane reactor, is the fact that the reaction and separation aspects of the process are combined in to one single unit. This prevents the need for additional separation and recycling units, as a result, the process becomes more greener and environmentally sustainable. Moreover, membrane reactors can improve the conversion and selectivity of the reactions, reduce mass transfer limitations and have a greater thermal stability, as opposed to the conventional reactors (Zhang et al., 2018).

In this communication, we will discuss renewable fuel production routes and technologies in detail, which include biofuels, hydrogen and the FT process. The advantages of membrane reactors will then be highlighted and elaborated upon compared to conventional reactors, and their environmental benefits. An in-depth review of membrane reactors for renewable fuel production will then be conducted to assess how conventional processes are intensified.

\section{Fuel production routes}

Membrane technology has been applied to biofuels and hydrogen fuels, and for FT synthesis. Biofuels are most commonly produced by transesterification; this consists of homogeneous catalytic transesterification and heterogeneous catalytic transesterification (Cannilla et al., 2018). Hydrogen can be produced by using fossil fuels as the feedstock (Wen et al., 2018). This includes steam reforming, partial oxidation and autothermal reforming. In addition, hydrogen can be produced by biological processes and TCT, such as pyrolysis, gasification and water splitting operations.

\subsection{Biofuel Production}

There are many well established methods and technologies for producing biodiesel fuel. It has been found that vegetable oils and animal fats are suitable for alteration to reduce their viscosities so that they can be used as diesel engine fuels (Abbaszaadeh et al., 2012). Typically, biofuels can be obtained by direct use and blending (Keskin et al., 2008), micro-emulsions (Ramadhas et al., 2004), pyrolysis (Yusuf et al., 2011) and transesterification (Aca-Aca et al., 2018). However, transesterification is commonly used to produce biofuels in membrane reactors.

The transesterification of oils (triglycerides) with alcohol produces biodiesel (fatty acid alkyl esters, FAAE) as the main product, and glycerine as a by-product. Figure 1 illustrates the transesterification reaction. The conversion of triglycerides to diglycerides takes place first, which is subsequently followed by the conversion of diglycerides to monoglycerides and then of monoglycerides to glycerol, this yields one methyl ester molecule from each glyceride at each step (Ma and Hanna, 1999). The transesterification reaction can take place with a homogeneous or heterogeneous catalyst. A homogeneous catalyst has the same phase as the reactants used, which in this case is liquid. On the 
contrary, if the catalyst is present in a different phase, then it is a heterogeneous catalytic reaction. Commercial biodiesel is typically produced by homogenous catalysed transesterification; this is because it has a lower production cost (Sharma et al., 2009).

\subsubsection{Homogeneous catalytic transesterification}

Homogeneous catalysts for transesterification can be classified into basic and acidic catalysts (Bing and Wei, 2019). The transesterification reaction using basic catalysts often needs raw materials of a high purity and requires an additional separation of the catalyst, products and side products at the end of the reaction. Biodiesel is typically produced using a homogeneous base catalyst such as alkaline metal alkoxides and hydroxides, and sodium or potassium carbonates. Mainly sodium or potassium hydroxides have been used for the basic methanolysis reaction, within a concentration range of 0.4 to $2 \% \mathrm{w} / \mathrm{w}$ of oil. Homogeneous base catalysts are often preferred to be used in industry due to high conversions and catalytic activity, and the fact that they are widely available and economical to use (Abbaszaadeh et al., 2012; Aransiola et al., 2014). Transesterification reactions using base catalysts are conducted at low temperatures and pressures (333-338 K and 1.4-4.2 bar) with catalyst concentrations of (0.5-2 wt\%) (Abbaszaadeh et al., 2012; Lotero et al., 2006).

Homogeneous base catalysts limit the process because of the sensitivity to the purity of the reactants, free fatty acid content, as well as to the water concentration of the sample. When there is a substantial amount of free fatty acids and water present in the oil, the oil is converted to soap as opposed to biodiesel. The free fatty acids present in the oil will react with the base catalyst to aid the production of soaps, which inhibits the separation of biodiesel, glycerine and wash water (Meher et al., 2006). The presence of water makes the reaction change slightly to saponification, as a result, the base catalyst is used to produce the soap and so the catalyst efficiency decreases. The accumulation of soap leads to an increase in viscosity and gel formation, which diminishes the ester yield and makes the removal of glycerol challenging. Hence, the side reactions such as hydrolysis and saponification should be kept to a minimum, in order to, enhance catalyst productivity (Enweremadu and Mbarawa, 2009).

Another type of homogeneous catalyst for the transesterification reaction is an acid catalyst. This type of catalyst is well suited for feedstocks which have a high free fatty acid content which are of a lower grade and inexpensive. The types of acid catalysts typically used are sulphuric, hydrochloric, sulfonic and phosphoric acids. These type of catalysts can produce customised biodiesel, as the properties of the fuel can be modified based on the fatty acids existing in the feed, and subsequently the fatty esters found in the product (Kiss, 2009). Acid catalysed homogeneous transesterification begins by mixing the oil directly with the acidified alcohol, which allows separation and transesterification to occur simultaneously in one single step, with the alcohol playing the role of both solvent and esterification reagent (Cerveró et al., 2008). Using excel alcohol in the reaction leads to a reduction in the reaction 
time needed for the acid catalysed homogeneous reaction. Therefore, Bronsted acid catalysed transesterification requires the use of high catalyst concentration and a high molar ratio as to shorten the reaction time (Enweremadu and Mbarawa, 2009).

Acid catalysed homogeneous transesterification demonstrates superiority over base catalysed transesterification due to its low susceptibility to the presence of free fatty acids in the feedstock. On the other hand, acid catalysed transesterification is highly sensitive to the presence of water. For example, it has been observed that $0.1 \mathrm{wt} \%$ of water in the reaction mixture can affect the ester product yields in the transesterification of vegetable oil with methanol, with the reaction nearly fully inhibited at 5 wt.\% water concentration (Cerveró et al., 2008). In addition, acid catalysed homogeneous transesterification can lead to equipment corrosion, issues with recycling, formation of by-products, increased reaction temperatures, long reaction times, slow rate of reaction and a weak catalytic activity (Di Serio et al., 2007; Goff et al., 2004).

\subsubsection{Heterogeneous catalytic transesterification}

Heterogeneous catalysts demonstrate superiority over homogeneous catalysts due to their ease of separation from the reaction mixture and reuse. In addition, using heterogeneous catalysts for transesterification reactions does not cause the production of soap (Wang and Yang, 2007). Lower production costs and higher efficiencies can be achieved with the use of these catalysts due to the elimination of several process steps such as, washing/recovery of biodiesel/catalyst. The heterogeneous catalytic transesterification process can operate in extreme reaction conditions, between $70-200^{\circ} \mathrm{C}$ to obtain a product yield of greater than $95 \%$ using $\mathrm{MgO}, \mathrm{CaO}$, and $\mathrm{TiO}_{2}$ catalysts (Singh and Fernando, 2007). An economic assessment of homogeneous and heterogeneous processes in large scale biodiesel production plants, has previously demonstrated the benefits of heterogeneous catalytic processes with regards to higher biodiesel yields and higher glycerine purities, as well as low catalyst costs and maintenance (Kiss et al., 2010).

Heterogeneous catalysts for transesterification can be classified into solid-base or solid-acid. Majority of the heterogeneous solid catalysts are base or basic oxides, as they are more active than the solid-acid catalysts. Basic zeolites, alkaline earth metal oxides and hydrotalcites are the most prominent solidbase catalysts used for the transesterification reaction (Kouzu and Hidaka, 2012). Solid base catalysts have demonstrated higher activity than the solid acid catalysts (Abbaszaadeh et al., 2012). Metal oxide catalysts such as, $\mathrm{CaO}$ and $\mathrm{MgO}$ are relatively cheap and if they have a high catalytic activity and stability, utilising them as catalysts would be economically desirable to produce biodiesel. Nevertheless, $\mathrm{CaO}$ has been found to leach in to the reaction mixture, as a result the metal ions would have to be extracted from the product by water washing, and so the benefits of using a heterogeneous catalyst would be gone. Despite this, $\mathrm{CaO}$ is still predominantly used as a solid-base catalyst and has shown a 
long catalyst lifetime, high activity, low methanol solubility and does not require extreme operating conditions (Liu et al., 2008).

Heterogeneous solid-acid catalysts have a variety of acid sites with varying strengths of Bronsted or Lewis acidity, as opposed to homogeneous acid catalysts. Solid-acid catalysts are unaffected by free fatty acid content, allow simultaneous esterification and transesterification (Dalai et al., 2006), easy catalyst removal from product stream, and prevent corrosion (Patil and Deng, 2009). Typical solid-acid catalysts used for the transesterification reaction are Nafion-NR50, sulphated zirconia and tungstated zirconia due to the acidic strength of the active sites. The catalyst which depicts a higher selectivity towards methyl esters and glycerol is Nafion as it has the strongest acid strength (Abbaszaadeh et al., 2012).

\subsection{Hydrogen production}

Hydrogen can be produced from a primary energy source, such as fossil fuels, and can then be used as a fuel either for direct combustion in an internal combustion engine, or in a fuel cell. Another method of producing hydrogen is from renewable resources, which can be from biomass or water (Edrisi and Abhilas, 2016). If biomass is used as the feedstock, then hydrogen can be obtained by means of thermochemical and biological processes. Thermochemical processes largely consist of pyrolysis, gasification, combustion and liquefaction; whereas biological processes consist of direct and indirect bio-photolysis, dark fermentation, photo-fermentation and sequential dark and photo-fermentation. More recent hydrogen production methods consist of electrolysis, thermolysis and photo-electrolysis, which require water as the only raw material. The various routes for hydrogen production are depicted in Figure 2 (Nikolaidis and Poullikkas, 2017).

\subsubsection{Production of hydrogen from fossil fuels}

The main method of producing hydrogen from fossil fuels is hydrocarbon reforming and pyrolysis. Until now, hydrogen was produced from $48 \%$ natural gas, $30 \%$ from heavy oils and naphtha, and 18\% from coal. The production of hydrogen from fossil fuels has remained as the dominant method in the world hydrogen supply because the production costs are strongly correlated to the fuel prices which are maintained at an acceptable level (Nikolaidis and Poullikkas, 2017).

The steam reforming method essentially consists of a $\mathrm{HC}$ and steam reacting together to form hydrogen and carbon oxides by using a catalyst. The main steps in this reaction are, synthesis gas (syngas) production, water-gas shift (WGS) and methanation or gas purification. The raw materials used for this reaction can be methane, natural gas, combinations of light hydrocarbons, and light and heavy naphtha (Balthasar, 1984). The steam reforming reaction conditions are high temperatures, pressures (up to 3.5 $\mathrm{MPa}$ ) and steam-to-carbon ratios of 3.5. This is so that the desired hydrogen purity can be achieved, as well as, reducing the coke formation on the solid catalyst surface (Ersöz 2008). Once reforming is 
complete, the product stream is passed into a WGS reactor and a heat recovery step where the CO reacts with the steam to produce more hydrogen. Finally, the mixture is taken through $\mathrm{CO}_{2}$ removal and methanation, or through pressure-swing absorption (PSA), which allows a hydrogen purity of approximately $100 \%$ to be obtained (Steinberg and Cheng, 1989). The main chemical reactions that take place for steam reforming are depicted below with respect to each unit operation as follows (Holladay et al., 2009; Nikolaidis and Poullikkas, 2017):

Reformer: $\quad \mathrm{C}_{\mathrm{n}} \mathrm{H}_{\mathrm{m}}+\mathrm{nH}_{2} \mathrm{O} \rightarrow \mathrm{nCO}+\left(\mathrm{n}+\frac{1}{2} \mathrm{~m}\right) \mathrm{H}_{2}$

WGS reactor: $\mathrm{CO}+\mathrm{H}_{2} \mathrm{O} \rightarrow \mathrm{CO}_{2}+\mathrm{H}_{2}$

Methanator: $\quad \mathrm{CO}+3 \mathrm{H}_{2} \rightarrow \mathrm{CH}_{4}+\mathrm{H}_{2} \mathrm{O}$

Steam methane reforming (SMR) is the most widely used method for hydrogen production, with a conversion efficiency of approximately $74-85 \%$. Steam and methane are reacted at $850-900^{\circ} \mathrm{C}$ in the presence of a nickel-based catalyst to produce syngas, and a hydrogen purity of $99.99 \%$ can be achieved when PSA is utilised to remove the hydrogen (Chen et al., 2008).

Partial oxidation method is another route for converting steam, oxygen and hydrocarbons to hydrogen and carbon oxides. The non-catalytic partial oxidation of hydrocarbons usually occurs with flame temperatures of around $1300-1500^{\circ} \mathrm{C}$ to ensure that complete conversion and the prevention of soot formation is achieved (Rostrup-Nielsen, 2003). The catalytic process operates at $950^{\circ} \mathrm{C}$, with the feedstock ranging from methane to naphtha (Steinberg and Cheng, 1989). Once sulphur has been removed from the HC feedstock, pure oxygen $\left(\mathrm{O}_{2}\right)$ is required to partially oxidise the HCs, and the resultant syngas product is upgraded in the same way as the steam reforming product (Balthasar 1984). Although using catalysts for partial oxidation can lead to lower reaction temperatures, there are issues with temperature control due to coke and hot spot formation because of the exothermic nature of the reactions. When using natural gas as the feedstock, the catalysts of choice tend to be nickel (Ni) or rhodium (Rh). However, Ni catalysts have a strong tendency to coke, and the cost of Rh has increased over the years (Holladay et al., 2009). The catalytic and non-catalytic reactions are depicted below (Nikolaidis and Poullikkas, 2017): 
Reformer (Catalytic): $\quad \mathrm{C}_{\mathrm{n}} \mathrm{H}_{\mathrm{m}}+\frac{1}{2} \mathrm{nO}_{2} \rightarrow \mathrm{nCO}+\frac{1}{2} \mathrm{mH}_{2}$

Reformer (Non-catalytic): $\quad \mathrm{C}_{\mathrm{n}} \mathrm{H}_{\mathrm{m}}+\mathrm{nH}_{2} \mathrm{O} \rightarrow \mathrm{nCO}+\left(\mathrm{n}+\frac{1}{2} \mathrm{~m}\right) \mathrm{H}_{2}$

WGS reactor: $\quad \mathrm{CO}+\mathrm{H}_{2} \mathrm{O} \rightarrow \mathrm{CO}_{2}+\mathrm{H}_{2}$

Methanator: $\quad \mathrm{CO}+3 \mathrm{H}_{2} \rightarrow \mathrm{CH}_{4}+\mathrm{H}_{2} \mathrm{O}$

The autothermal reforming (ATR) method combines the exothermic partial oxidation reaction with the endothermic steam reforming reaction to enhance hydrogen production. The reforming and oxidation reactions happen simultaneously in the ATR reactor (Eq.8) (Nikolaidis and Poullikkas, 2017).

$\mathrm{C}_{\mathrm{n}} \mathrm{H}_{\mathrm{m}}+\frac{1}{2} \mathrm{nH}_{2} \mathrm{O}+\frac{1}{4} \mathrm{nO}_{2} \rightarrow \mathrm{nCO}+\left(\frac{1}{2} \mathrm{n}+\frac{1}{2} \mathrm{~m}\right) \mathrm{H}_{2}$

The oxygen-to-fuel ratio and the steam-to-carbon ratio must be carefully controlled in order to control the reaction temperature and product gas composition, while preventing soot formation (Holladay et al., 2009). Using methane $\left(\mathrm{CH}_{4}\right)$ as the $\mathrm{HC}$ fuel for the ATR process, thermal efficiencies of $60-75 \%$ can be achieved, while the optimum reaction conditions are around $700^{\circ} \mathrm{C}$ for a steam-to-carbon ratio of 1.5 , and a oxygen-to-carbon ratio of 0.45 where a maximum hydrogen yield of 2.5 can be achieved (Ersöz, 2008; Holladay et al., 2009). This process can be expected to be favourable with the gas-toliquid industry because of the desirable gas composition for the FT process, the lower capital cost and the potential for economies of scale (Wilhelm et al., 2001).

The production of hydrogen from the pyrolysis of $\mathrm{HC}$ is also another common process, where the HC is subjected to thermal decomposition to produce hydrogen. The general reaction follows the route shown below:

Hydrocarbon specices $\left(\mathrm{C}_{\mathrm{n}} \mathrm{H}_{\mathrm{m}}\right) \rightarrow \mathrm{nC}+\frac{1}{2} \mathrm{mH}_{2}$ 
The pyrolysis process eliminates the WGS reaction and $\mathrm{CO}_{2}$ separation step, as a result, the capital investment of these large-scale plants is lower when compared to the steam reforming or partial oxidation methods. This leads to an approximately $25-30 \%$ reduction in the hydrogen production cost (Muradov, 1993).

\subsubsection{Production of hydrogen from renewable resources}

Even though HCs are the most common feedstock for hydrogen generation, it is imperative to investigate renewable and sustainable technologies due to the numerous environmental benefits of doing so. The depletion of fossil fuels, and the increase of GHGs emissions has led to the increase of finding alternative methods to produce hydrogen. Hydrogen production from biomass, and water splitting will be briefly discussed.

Biomass can undergo thermochemical processes to produce hydrogen, these processes are mainly pyrolysis and gasification. These processes are environmentally sustainable as they have zero GHGs emissions (Fremaux et al., 2015). The pyrolysis of biomass consists of thermal degradation of the feedstock in the absence of oxygen under reaction conditions of 650-800 K and 0.1-0.5 MPa, to produce bio-oil, solid char and gaseous products. Pyrolysis of biomass can be categorised further into fast pyrolysis and slow pyrolysis. Slow pyrolysis is often not conducted because the main product of this process tends to be solid charcoal. In fast pyrolysis, the biomass feedstock is heated very quickly under anaerobic conditions to produce a vapour and a dark brownish bio-oil product. The gaseous products contain $\mathrm{H}_{2}, \mathrm{CH}_{4}, \mathrm{CO}, \mathrm{CO}_{2}$, and other gases depending on the biomass feedstock used (Jalan and Srivastava, 1999; Ni et al., 2006). Hydrogen can be produced directly using fast or flash pyrolysis, if high temperatures and a sufficient volatile phase residence time is given as follows ( $\mathrm{Ni}$ et al., 2006):

Biomass + heat $\rightarrow \mathrm{H}_{2}+\mathrm{CO}+\mathrm{CH}_{4}+$ other products

The $\mathrm{CH}_{4}$ produced can be further upgraded by SMR to produce additional hydrogen:

$\mathrm{CH}_{4}+\mathrm{H}_{2} \mathrm{O} \rightarrow \mathrm{CO}+3 \mathrm{H}_{2}$

To enhance the hydrogen production, the WGS reaction can be applied as follows:

$\mathrm{CO}+\mathrm{H}_{2} \mathrm{O} \rightarrow \mathrm{CO}_{2}+\mathrm{H}_{2}$

Biomass gasification is another thermochemical route for producing hydrogen. Here, the biomass can be gasified at high temperatures in excess of $1000 \mathrm{~K}$; the partial oxidation of biomass will take place to 
produce gas and solid char. The charcoal will subsequently be reduced to $\mathrm{H}_{2}, \mathrm{CO}, \mathrm{CO}_{2}$ and $\mathrm{CH}_{4}$. This can be expressed as:

Biomass + heat + steam $\rightarrow \mathrm{H}_{2}+\mathrm{CO}+\mathrm{CO}_{2}+\mathrm{CH}_{4}+$ light and heavy hydrocarbons + char (13)

The gasification of biomass takes place in the presence of oxygen $\left(\mathrm{O}_{2}\right)$ gas, as opposed to the pyrolysis of biomass reaction. Furthermore, the main aim of the gasification process is to produce predominantly gaseous products, and these products can then be further upgraded to produce hydrogen by steam reforming and the process can be further improved by using the WGS reaction. Biomass feedstock which has a moisture content of less than $35 \%$ is well suited to the gasification process (Demirbaş, 2002).

In addition to thermochemical processes, biological processes have also been developed to minimise waste and to enhance environmental sustainability. Majority of these processes operate at standard conditions, and so they are deemed to be more environmentally friendly and sustainable. In addition, these processes make use of renewable energy resources, and they contribute to waste recycling as the feedstocks they often require are waste materials (Das and Veziroğlu, 2001). The main biological processes for hydrogen generation are direct and indirect photolysis, photo and dark fermentations, and multi-stage or sequential dark and photo fermentation.

\subsection{Fischer-Tropsch (FT) synthesis}

The FT process converts synthetic gas to HCs. Figure 3 shows how the FT process can be utilised to produce liquid fuels (Hafeez et al., 2018). Essentially, any carbon source can be used as the feedstock for the FT process to obtain alternative fuels. The FT process can produce a wide range of products which can then be upgraded to obtain the desired hydrocarbon fractions. The FT reaction is highly exothermic and makes use of heterogeneous catalysts with reaction conditions of $300-350^{\circ} \mathrm{C}$ and high pressures (Guettel et al., 2008).

Current FT operates at low temperature for the production of liquid fuels. The basic FT reaction produces paraffinic or olefinic chains:

$\mathrm{nCO}+(2 \mathrm{n}+1) \mathrm{H}_{2} \rightarrow \mathrm{C}_{\mathrm{n}} \mathrm{H}_{2 \mathrm{n}+2}+\mathrm{nH}_{2} \mathrm{O}$

$\mathrm{nCO}+2 \mathrm{nH}_{2} \rightarrow \mathrm{C}_{\mathrm{n}} \mathrm{H}_{2 \mathrm{n}}+\mathrm{nH}_{2} \mathrm{O}$

Eq.14 is highly exothermic, and has a reaction enthalpy of $-150 \mathrm{~kJ}$ per mole of converted CO. The CO product can be converted to $\mathrm{CO}_{2}$ and hydrogen by the WGS reaction as seen in Eq.12 (Guettel et al., 
2008). Typical catalysts used for the FT process are iron, cobalt and ruthenium. However, the high cost of ruthenium means that iron and cobalt are most commonly used. One limitation of using an iron catalyst is its inhibition by the side product of water. On the contrary, its activity for the WGS reaction permits the use of $\mathrm{CO}_{2}$ containing gases or hydrogen exhausted syngas mixtures. Cobalt catalysts are found to higher activity and longer catalyst lifetime when compared to iron catalysts. On the other hand, cobalt tends to be more expensive than iron (Guettel et al., 2008; Van Der Laan and Beenackers 1999).

\section{Membrane reactors versus conventional systems for environmental applications}

A membrane reactor can be defined as a device that couples' reaction and separation within one single unit. Due to the significant problems faced with regards to the separation and purification of fatty acid methyl esters (FAME) from impurities, novel research into membrane reactors has been conducted in order to circumvent this costly problem, as well as optimise the production of biodiesel. According to research carried out by Cao et al. (2008b) on methanol recycling a membrane reactor for the production of biodiesel, it was found that using an inorganic membrane in the membrane reactor could remove the desired constituents during the reaction from the oil. The addition of a membrane also facilitates an increase in conversion, as the products permeate through the membrane and can be removed. This shifts the equilibrium in the forward reaction resulting in a higher yield of FAME, whilst reducing the amount of undesired side products. In addition, membrane reactors attain high conversion rates when compared to conventional ones due to the removal of undesired by-products (Baroutian et al., 2011).

The issue of immiscibility of methanol and oil arises in a conventional reactor as it leads to limited mass transfer (Dubé et al., 2007). Whereas, the two-phase nature of the mixture between the respective compounds is fundamental for the success of the membrane reactor. This is because the membrane acts as a barrier allowing methanol to permeate through, while preventing the oil droplets that were emulsified in the methanol from passing through due to its larger molecular size relative to the pore size of the membrane (Baroutian et al., 2011). As a result of this separation via a membrane, the mass transfer is not limited as was the case with the conventional reactor.

Using conventional reactors for biodiesel production requires a purification stage as the biodiesel produced must be of a certain purity. The primary method of purifying FAME is by water washing the non-polar phase, which involves the removal of any residual catalyst and small quantities of glycerol, as well as other impurities which are soluble in water. However, the non-polar phase of FAME is not easily removed from the water layer. Therefore, it requires more expenditure on separation equipment. This leads to the production of a significant amount of wastewater that will need further treatment. In contrast, the membrane reactor was found to have greatly reduced the difficulty in separating and purifying FAME from impurities, as evidenced by the research of Cao et al. (2008b) showing a drastic reduction in the amount of water washing to purify FAME (Atadashi et al. 2011). 
The use of a membrane reactors is more economically viable than conventional ones. This is linked to the fact that such processes are intensified by combining the reaction and separation aspects in one unit. This can allow for the potential reductions in separation and recycling units, which would result in the process becoming less energy intensive. Therefore, efficiency increase is also anticipated. Furthermore, the intrinsic properties of inorganic membranes make them possess a high thermal threshold. Due to their thermal stability, membrane reactors can be used for reactions that are highly exothermic (Dubé et al., 2007).

As a result of the biodiesel production process being intensified with the operation of a catalytic membrane reactor, the energy consumption has been significantly reduced. An experiment conducted by Dubé et al. (2007) stated that the highest reported reaction temperature used in the membrane reactor was $70^{\circ} \mathrm{C}$; in comparison with using a solid basic catalyst or solid acid catalyst for transesterification, the reactions temperatures are in the ranges of $180-200^{\circ} \mathrm{C}$ (Jitputti et al., 2006; Di Serio et al., 2006) and $200-300^{\circ} \mathrm{C}$ (Chen et al., 2007; Furuta et al., 2004; Jitputti et al., 2006). This shows that less electricity is required to be generated for energy for the membrane reactor by burning fossil fuels, which is detrimental to the welfare of the environment. Burning fossil fuels are notorious for producing undesired particulates into the air, such as carbon dioxide and sulphur dioxide; these emissions play a direct role in the production of acid rain which go on to have negative effects on plants, aquatic animals and damage infrastructures. With the use of membrane reactors, these harmful effects on the environment are minimised (Kampa and Castanas, 2008).

The issue of large amounts of wastewater produced due to the separation and purification stages is an environmental concern. The increase of wastewater effluents could potentially lead to an increase in the quantity of chemicals and solvents that are toxic to the environment (Shuit et al., 2012). However, if twenty million tonnes per year of biodiesel is produced (Licht and Agra, 2007) with a density of 900 $\mathrm{kg} / \mathrm{m}^{3}$ (Knothe et al., 2005), the amount of wastewater that is produced by conventional separation methods would be 59 billion gallons. On the other hand, by using a membrane reactor, the amount of wastewater will significantly reduce to 12 billion gallons. Therefore, a membrane reactor could potentially make the purification step and the water washing procedure, redundant as using a catalytically active membrane would not require water washing for purification. Therefore, the problem of wastewater can be dealt with. This in turn would drastically decrease the probability of chemicals and solvents harming the environment, due to the contaminants that comes with wastewater. Furthermore, glycerol removal can be done via the use of a membrane reactor separating it from the FAME phase during the reaction which makes the requirement of water washing all the more unnecessary (Shuit et al., 2012).

\section{Membrane reactors for renewable fuel production}


Typically, a membrane reactor can be classified into four distinct parts. These are, the design of the reactor (e.g. distributor, extractor or contactor), type of membrane used (e.g. porous, organic or inorganic), catalyst presence in the membrane; and finally, the reaction that is taking place inside the membrane reactor (Mueller et al., 2008). Furthermore, this type of reactor configuration has been proven to enhance the product yield and selectivity of the reaction (Marcano and Tsotsis, 2002). Figure 4 represents a schematic comparing conventional reaction system with a combined membrane and reactor system (Lipnizki et al., 1999). The main benefit of using the combined membrane and reactor system is the fact that the capital and operating costs are significantly reduced because an intermediate separation step is not required (Marcano and Tsotsis, 2002). Membrane technology has recently been applied to the production of renewable fuels due to its advantages over the conventional reactors.

\subsection{Membrane reactors for biofuel production}

For biodiesel production, the most important role of the membrane is to either remove the glycerol from the product (Guerreiro et al., 2006; Saleh et al., 2010) or to preserve the unreacted glycerides in the membrane (Baroutian et al., 2011; Dubé et al., 2007). The two main methods of producing biodiesel using membrane reactors is separation by oil droplet size (Cao et al., 2008a; 2008b) or by utilising catalytic membranes (Guerreiro et al., 2006; Guerreiro et al., 2010; Shao and Huang, 2007). Membrane separation based on oil droplet size involves a microporous membrane which is typically a ceramic or microporous membrane (Figure 5) (Shuit et al., 2012). A study conducted by Baroutian et al. (2010) has demonstrated that this particular separation. Methanol recovery during the transesterification of palm oil in a ceramic membrane reactor using $\mathrm{TiO}_{2} / \mathrm{Al}_{2} \mathrm{O}_{3}$ catalyst was also demonstrated. The methanol molecules were able to pass through the membrane with the products because of its small molecular size. It is necessary to recover the methanol as it is one of the most essential reactants needed for transesterification. The ceramic membrane was therefore attached to a simple distillation unit to remove the methanol from the membrane permeate stream. In a further study conducted by Baroutian et al. (2011), a packed bed membrane reactor was used for the production of biodiesel using a potassium hydroxide catalyst supported on palm shell activated carbon. The results showed that the highest conversion of palm oil to biodiesel in the reactor was found at $70^{\circ} \mathrm{C}$ utilising $157.04 \mathrm{~g}$ of catalyst per unit volume of the reactor and a cross flow circulation velocity of $0.21 \mathrm{~cm} / \mathrm{s}$. The biodiesel product obtained was compared with standard specifications based on the physical and chemical properties. It was concluded that high quality palm oil diesel was obtained by using this membrane reactor configuration.

Dubé et al. (2007) developed a two-phase membrane reactor to produce biodiesel from canola oil and methanol. The transesterification reaction of canola oil was achieved via acid or base catalysis. The results showed that increasing the temperature, catalyst concentration and the feed flow rate would 
significantly increase the conversion of oil to biodiesel. Furthermore, the two-phase membrane reactor was highly useful in separating the unreacted canola oil from the biodiesel product which resulted in biodiesel of a high purity and maintained the reaction equilibrium to the product side.

Cao et al. (2008a) conducted a high-purity fatty acid methyl ester production from different lipids such as canola, soybean, palm and yellow grease lipids, combined with methanol using a membrane reactor. The membrane system consisted of reaction and separation within one single unit, which allowed a continuous mixing of the raw materials, and kept a desirable molar ratio of methanol to lipid in the reaction loop whilst maintaining two phases during the reaction. The biodiesel was analysed using GC and it was found that the product quality was high. In addition, the quality of biodiesel was significantly affected by the composition of the fatty acids in the feedstock. Cao et al. (2008a) further utilised a membrane reactor to produce a permeate stream which readily phase separates at room temperature in to a fatty acid methyl ester (FAME) rich non-polar phase and a methanol- and glycerol-rich polar phase. The results showed that the highest recycle ratio of $100 \%$ produced a FAME concentration of between 85.7 to $92.4 \mathrm{wt} \%$ in the FAME-rich non-polar phase. Furthermore, decreasing the methanol:oil ratio to 10:1 in the reaction system while keeping a FAME production rate of $0.04 \mathrm{~kg} / \mathrm{min}$ resulted in a FAME product with a high purity.

Another method of producing biodiesel is by using a catalytic membrane. This involves a dense nonporous polymer membrane, for example poly (vinyl alcohol) (PVA). This type of configuration works based on the interaction between the target component and the polymer functional groups of the membrane (Shuit et al., 2012). Guerreiro et al. (2006) investigated the transesterification of soybean oil over sulfonic acid (functionalised) polymeric membranes using solid catalysts at $60^{\circ} \mathrm{C}$ and atmospheric pressure. The catalytic membrane used for the transesterification studies was a Nafion one with ionexchange resins and poly (vinyl alcohol) membranes containing sulfonic groups. The results showed that PVA polymers crosslinked with sulfosuccinic acid, are more active than the commercial Nafion membranes used due to the higher content of sulfonic groups. A further study conducted by Guerreiro et al. (2010) showed that the most desirable results were obtained with a hydrophilic membrane using solid base catalysts. In addition, the same sample of the membrane was utilised in seven consecutive runs to assess the catalyst stability. It was found that these catalysts were most active in the transesterification of soybean oil with methanol and can also be reused for many runs without the risk of further reactivation.

Shi et al. (2010) developed a novel organic-inorganic hybrid membrane as a heterogeneous acid catalyst for biodiesel production prepared from zirconium sulphate $\left(\mathrm{Zr}\left(\mathrm{SO}_{4}\right)_{2}\right)$ and sulfonated poly(vinyl alcohol) (SPVA). It was found that the $\mathrm{Zr}\left(\mathrm{SO}_{4}\right)_{2}$ particles were better dispersed in SPVA matrix as a result of the stronger interaction between $\mathrm{Zr}\left(\mathrm{SO}_{4}\right)_{2}$ and SPVA compared with $\mathrm{Zr}\left(\mathrm{SO}_{4}\right)_{2} /$ poly(vinyl alcohol) (PVA) hybrid membrane. It was found that the conversions of free fatty acid (FFA) in acidified oil were $94.5 \%$ and $81.2 \%$ for $\mathrm{Zr}\left(\mathrm{SO}_{4}\right)_{2} / \mathrm{SPVA}$ and $\mathrm{Zr}\left(\mathrm{SO}_{4}\right)_{2} / \mathrm{PVA}$ catalytic membranes, respectively. 
Furthermore, the $\mathrm{Zr}\left(\mathrm{SO}_{4}\right)_{2} / \mathrm{SPVA}$ catalytic membrane has a higher performance to the $\mathrm{Zr}\left(\mathrm{SO}_{4}\right)_{2} / \mathrm{PVA}$ catalytic membrane. Aca-Aca et al. (2018) conducted a catalytic performance study for biodiesel production by a novel catalytically active membrane from polyacrylic acid (PAAc) crosslinked with 4,40-diamino-2,20-biphenyl sulfonic acid (PAAc-BDSA). It was found that the methyl ester yield follows the order 90, 92 and 73\% for PVA-88-SSA, PVA-99-SSA and PAAc-BDSA, respectively. Higher diffusion coefficients and sorption of methanol and glycerol by PAAc-BDSA membrane make it suitable to use in membrane reactors for biodiesel production and glycerol separation simultaneously. Zhu et al. (2010) prepared Poly(styrene sulfonic acid) (PSSA)/Poly(vinyl alcohol) (PVA) blend membranes by solution casting, and were employed as heterogeneous acid catalysts for biodiesel production from acidic oil obtained from waste cooking oil (WCO). The membranes were annealed at varying temperatures in order to increase their stability. The results of esterification of acidic oil show that the conversion was higher with the PVA content in the membrane at a constant PSSA content. Furthermore, the catalytic membrane thickness had negligible effect on the conversion at the end. The membrane annealed at $120^{\circ} \mathrm{C}$ exhibited superior catalytic performance among the membranes, with a stable conversion of $80 \%$ with the runs.

Catalytic membranes posses the ability to incorporate a catalyst depending on its formulations and functionality. A membrane without the incorporated catalyst can also be referred to as a catalytically inert membrane where the catalyst is added to the reactants, but not implanted inside the membrane (Buonomenna et al. 2010). The main catalytically inert membranes found in biodiesel production are the filtanium ceramic membranes (Cao et al. 2008a; 2008b), $\mathrm{Ti}_{2} / \mathrm{O}_{2} / \mathrm{Al}_{2} \mathrm{O}_{3}$ in ceramic membrane (Baroutian et al. 2011; Baroutian et al. 2010), and carbon membrane (Dubé et al., 2007) with the separation principle based on the oil droplet sizes. The pore sizes of these membranes can vary from 0.02-0.05 $\mu \mathrm{m}$ (Baroutian et al., 2010). The catalysts used for the membranes without the incorporated catalyst include sulphuric acid $\left(\mathrm{H}_{2} \mathrm{SO}_{4}\right)$ (Dubé et al., 2007) and potassium hydroxide/sodium hydroxide solution $(\mathrm{KOH} / \mathrm{NaOH})$ (Baroutian et al., 2010). Firstly, a pre-determined quantity of oil and a homogeneous mixture of methanol/KOH are passed into a mixing vessel for pre-mixing. The reaction mixture is then heated to the target reaction temperature, before being passed into the membrane reactor. The permeate stream is comprised of biodiesel, methanol, glycerol and catalysts (Baroutian et al., 2010; Dubé et al., 2007). Oil droplets which have a pore size larger than the membrane pore size $(12 \mu \mathrm{m})$ (DeRoussel et al., 2001) are trapped on the retentate side and are subsequently recycled back to the mixing vessel (Cao et al., 2008b). The permeate stream can be separated into polar and non-polar phases. The non-polar phase is made up of methanol, trace amounts diglycerides and catalysts (Cao et al. 2008a; 2008 b). On the other hand, the polar phase is comprised of glycerol, methanol, catalysts and biodiesel (Cao et al., 2008b). It has been observed that this type of catalytic membrane reactor is able to achieve an oil-to-biodiesel conversion of $\geq 90 \%$ for both $\mathrm{H}_{2} \mathrm{SO}_{4}$ and $\mathrm{KOH}$ catalysts (Dubé et al., 2007). In addition, using activated carbon as a catalyst support resulted in an increase in conversion by 
93.5\% (Rahimpour, 2015). The methanol that permeates through the membrane is recycled back to the reactor to lessen the overall methanol-to-oil molar ratio (Cao et al., 2007). Methanol can be recycled back to the reactor by distilling the methanol from the non-polar phase, and direct recycling of the polar phase (Rahimpour, 2015).

Baroutian et al. (2011) used a packed bed membrane reactor, which utilised activate carbon as the catalyst support to prevent the permeation of catalysts through the membrane. The catalyst was prepared by adding activated carbon into a potassium hydroxide $(\mathrm{KOH})$ solution. The mixture was then agitated for a period of 24 hours and a temperature of $25^{\circ} \mathrm{C}$. The catalysts were then packed inside the $\mathrm{TiO}_{2} / \mathrm{Al}_{2} \mathrm{O}_{3}$ membrane reactor. It was reported that for this particular configuration, the oil conversion obtained was higher than that of the membrane reactor with the addition of $\mathrm{H}_{2} \mathrm{SO}_{4}$ or $\mathrm{KOH}$ catalysts (Baroutian et al., 2011).

A membrane which incorporates the catalyst has the catalyst immobilised in the polymeric matrix and is more commonly referred to as a catalytically active membrane. The membrane can be made catalytically active by the heterogenization of the homogeneous catalysts, or the incorporation of heterogeneous catalysts inside the polymeric matrix. This particular type of membrane combines the reaction and separation in a single step, which is essentially the same principle of reactive separation (Buonomenna et al., 2010), thus the membrane can be regarded as a separative reactor (Stankiewicz, 2003). Until now, poly(vinyl alcohol) (PVA) membranes are the only conveyed polymer membranes that have been used for biodiesel production (Sarkar et al., 2010). This is due to their high hydrophilicity, good thermal properties and good chemical resistance (Guan et al., 2006).

\subsection{Membrane reactors for hydrogen production}

Recently, membrane reactors for hydrogen production have gained increasing attention due to their superiority over the conventional reaction systems. Typically, packed bed membrane reactors (PBMR) have been used for hydrogen production. However, novel systems such as fluidised bed membrane reactors (FBMR) and micro membrane reactors (MMR) have now been employed due to better mass and heat transfer (Gallucci et al., 2013).

In a packed bed membrane reactor, the catalyst is packed in a fixed bed configuration, and is in contact with a perm-selective membrane. The most popular and widely used configuration is the tubular one, where the catalyst can be packed in the membrane tube (Figure 6a) or in the shell side (Figure 6b) (Gallucci et al., 2013). For multi-tubular membrane reactor configurations, packing the catalyst within the tube is preferred due to construction issues and for bed-to-wall mass and heat transfer limitations which can have damaging effects if the catalyst is placed within the shell side. It is common to use a sweep gas in the permeation side of the membrane to ensure that the permeation hydrogen partial pressure is at the lowest for minimising the membrane area needed for hydrogen removal. The use of a sweep gas in the permeation side can allow the packed bed membrane reactor to be used in both co- 
current and counter-current modes. The counter-current mode configuration can lead to different partial pressure profiles in reaction and permeation sides when compared to the co-current mode (Gallucci et al., 2008).

Gallucci et al. (2008) created a mathematical model for a palladium membrane reactor packed with a co-based catalyst. The results were obtained for both co and counter current modes in terms of ethanol conversion and molar fraction versus temperature, pressure, the molar feed flow rate ratio and axial coordinate. The results demonstrated that co-current mode membrane reactor configuration generated higher ethanol conversions as opposed to the counter-current mode; however, the counter-current mode allows a larger amount of hydrogen to be extracted from the reaction zone. Basile et al. (2008) studied the steam reforming of methanol by using a dense $\mathrm{Pd}-\mathrm{Ag}$ membrane reactor and a fixed bed reactor, and a constant sweep gas flow rate in counter current mode was employed. Both reactors were packed with a catalyst based on $\mathrm{CuOAl}_{2} \mathrm{O}_{3} \mathrm{ZnOMgO}$, and had an upper temperature limit of around $350^{\circ} \mathrm{C}$. It was found that the catalyst showed high activity and selectivity towards the $\mathrm{CO}_{2}$ and $\mathrm{H}_{2}$ formation in the range of temperatures used. It was concluded that the membrane reactor demonstrated higher conversions than the fixed bed reactor under the same operating conditions. In addition, at an operating temperature of $300^{\circ} \mathrm{C}$ and a $\mathrm{H}_{2} \mathrm{O} / \mathrm{CH}_{3} \mathrm{OH}$ molar ratio greater than 5:1, the membrane reactor achieved a $100 \%$ methanol conversion.

The application of a tube in shell configuration is noted to be one of the main methods of increasing the membrane area in the packed bed (Tosti et al., 2008). This has been demonstrated by Buxbaum (2002) where the catalyst is loaded in the shell side of the reactor while the membrane tubes are connected to a collector for the pure hydrogen. Furthermore, it is possible to use a catalyst in a separate chamber, in which case the chamber acts as a pre-reforming zone where the largest temperature profiles are found. This means that the membranes can operate almost isothermally.

Another method of increasing the membrane area per volume of reactor is by using a hollow fibre configuration. Kleinert et al. (2006) conducted the partial oxidation of methane for hydrogen production in a hollow fibre membrane reactor. A phase inversion spinning technique was used to produce the perovskite membranes made from $\mathrm{Ba}(\mathrm{Co}, \mathrm{Fe}, \mathrm{Zr}) \mathrm{O}_{3-\mathrm{d}}(\mathrm{BCFZ})$ powder. The results demonstrated that a methane conversion and $\mathrm{CO}$ selectivity of $82 \%$ and $83 \%$ was achieved respectively. Furthermore, the membrane proved to be quite stable under the reaction conditions used. In addition, Maneerung et al. (2016) used a Triple-layer hollow fibre catalytic membrane reactor (T-HFCMR) consisting of: (1 )Nibased catalyst (outer) layer; (2) porous inorganic support (middle) layer; and (3) ultra-thin Pd-based membrane (inner) layer, for the production of hydrogen. It was observed that the high hydrogen permeability of the ultra-thin Pd-based membrane led to $84 \%$ of the total hydrogen to be separated from the reaction side. Furthermore, the continuous permeation of hydrogen from the reaction side significantly enhanced the reaction conversion. Since the membrane is not exposed to directly to the 
external surface, mechanical damages of the Pd-Ag membrane can be prevented which is beneficial for practical applications.

A more recent approach to produce hydrogen is using fluidised bed membrane reactors. This consists of a bundle of hydrogen selective membranes, which are submerged to a catalytic bed and demonstrate a bubble or turbulent flow regime. Fluidised bed membrane reactors are found to reduce bed-to-wall mass transfer limitations, but also enable the reactor to function isothermally. This type of configuration can be used for performing the autothermal reforming of hydrocarbons to produce hydrogen.

A fluidised bed membrane reactor schematic is shown in figure 7 to produce hydrogen and methanol (Rahimpour and Bayat, 2011). The production of methanol occurs in the inner tube and provides heat to the endothermic side. The cyclohexane dehydrogenation to benzene takes place in the second tube which is coated by a Pd-Ag membrane layer. The hydrogen produced from the dehydrogenation of cyclohexane diffuses in to the outer tube/permeation side. The results from this study were compared to those obtained from a thermally coupled membrane reactor at the same reaction operating conditions. It was found that the hydrogen recovery yield and benzene production of the fluidised bed membrane reactor was $5.6 \%$ and $8.52 \%$ greater to that of the thermally coupled membrane reactor. This is due to the low pressure drop and the negligible mass and heat transfer limitations in the fluidisation process. It was concluded that this membrane reactor configuration is feasible for the production of pure hydrogen (Rahimpour and Bayat, 2011). In addition, Spallina et al. (2018) utilised Pd-based membranes for the production of pure hydrogen in a fluidised bed catalytic reactor for the autothermal reforming of ethanol. It was concluded that the reactor concept is feasible for the production of hydrogen, especially because a hydrogen recovery factor of $70 \%$ can be achieved.

Micro membrane reactors have recently been developed for hydrogen production. This is because membrane microreactors have enhanced mass and heat transfer (Constantinou et al., 2014) because of the shortened length of the microchannels, removal of mass transfer limitations (concentration polarisation), heightened process intensification by integrating various process steps in small scale process unit (Gallucci et al. 2013). Mejdell et al. (2009a, 2009b); Mejdell et al. (2009c) compared the performance of the same membrane in varying configurations. It was observed that by using the tubular configuration the extent of concentration polarisation is the limiting step for hydrogen permeation. On the other hand, the same membrane applied in a microreactor configuration, the concentration polarisation effect can be totally ignored (Mejdell et al., 2009c). Figure 8 shows a depiction of the microchannel reactor configuration used by Bredesen and co-workers (Mejdell et al., 2009b). The reactor is comprised of s-shaped microchannels which have a length of $13 \mathrm{~mm}$, and a section of $1 \mathrm{~mm}$ $\times 1 \mathrm{~mm}$. The membranes used are Pd based which have a thickness of less than $3 \mu \mathrm{m}$, this type of membrane configuration is able to tolerate differential pressures of greater than $470 \mathrm{kPa}$. 


\subsection{Membrane reactors for Fischer-Tropsch synthesis}

Recently, membrane reactors for FT synthesis have gained an increasing attention due to their advantageous properties. Membrane reactors for FT synthesis have the potential to be used in small or medium plants for future off-shore or biomass-to-liquid applications (Guettel et al., 2008). There are four concepts of using membranes for FT synthesis: distributed feed of reactants, in situ removal of water, forced-through membrane contactor and zeolite encapsulated catalysts (Figure 9) (Rohde et al., 2005b).

A catalytic membrane has the potential to offer a defined reaction zone, whilst the reactants are forced through the membrane by means of a pressure gradient. High gas-liquid mass transfer rates can be observed depending on the properties of the membrane, this leads to higher volume specific production rates. In a more recent concept, the products from the FT process are passed through a catalytic membrane which results in an altered product distribution. Therefore, the driving force for applying membrane technology to FT synthesis are: longer catalyst lifetime, higher product selectivity's and higher specific production rates (Rohde et al., 2005b).

The distributed feed of reactants through a membrane can enable better temperature control, and the selectivity of methane can be affected, by changing the $\mathrm{H}_{2} / \mathrm{CO}$ ratio. Since the activity and product selectivity rely heavily on the $\mathrm{H}_{2} / \mathrm{CO}$ ratio when using Co-based catalysts, distributed feeding can affect the gas phase composition positively (Rohde et al., 2005b).

Water is a side product formed during the FT process, and its accumulation in the gas phase can decrease the partial pressure of the reactants. This particular type of membrane configuration because high water partial pressures can result in re-oxidation and shorter catalyst lifetime. It has been observed that water can adversely affect the reaction rate and can encourage the formation of $\mathrm{CO}_{2}$ by the WGS reaction. By integrating the in situ removal of water membrane into the FT process, the rate of reaction can be enhanced, and shift the equilibrium in favour of CO production (Espinoza et al., 2000; Rohde et al., 2005a; Zhu et al., 2005). Espinoza et al. (2000) conducted a series of permeation experiments with silicalite-1/ZSM-5 and mordenite (on a- $\mathrm{Al}_{2} \mathrm{O}_{3} /$ stainless steel support) under non-reactive conditions typical for FT $\left(200-300^{\circ} \mathrm{C}\right.$ and $\left.2 \mathrm{MPa}\right)$. The results showed that mordenite membranes demonstrated high water fluxes $\left(\mathrm{PH}_{2} \mathrm{O}=2 \times 10^{-7} \mathrm{~mol} /(\mathrm{s} \mathrm{Pa} \mathrm{m} 2), 250^{\circ} \mathrm{C}\right)$ and desirable permselectivities. Rohde et al. (2005a) carried out experiments in a packed bed reactor with an integrated silica membrane. Although the membrane was found to show low permselectivities regarding the water under the FT reaction conditions, the shortcomings of the permselectivities can be overcome by the choice of $\mathrm{H}_{2}$ and $\mathrm{H}_{2} / \mathrm{CO}_{2}$ as the sweep gas. It was concluded that the increase in conversion of $\mathrm{CO}_{2}$ to long-chain hydrocarbons via the $\mathrm{CO}_{2}$ shift and FT process can be enhanced by the in situ removal of water, which results in higher product yields. 
A study conducted by Khassin et al. (2005) investigated the concept of forced-through flow membrane for FT synthesis by using thermally conductive contactor modules (plug-through contactor membrane, PCM). The synthesis gas enters through the internal void space, and then passes through the membrane which has a thickness of $2.5 \mathrm{~mm}$. In order to improve the thermal conductivity, copper can be applied during membrane production. It was observed that PCMs can offer lower pressure drops, high spacetime-yields at flat temperature profiles, larger reactor capacities, high gas-liquid mass transfer rates and low diffusive constraints. Furthermore, Bradford et al. (2005) utilised a monolith loop catalytic membrane reactor (ML-CMR) concept for Fischer-Tropsch synthesis (FTS) to evaluate the performance of a $\mathrm{P} / \mathrm{Pt}-\mathrm{Co} / \gamma-\mathrm{Al}_{2} \mathrm{O}_{3}$ catalyst in a prototype, tubular $\mathrm{CMR}$ and in a tubular, fixed-bed reactor. The synthesis gas was fed from the shell side to the alumina carrier material and passed through the membrane to the catalyst. The membrane allowed the produced hydrocarbons to be collected from the tube side.

The catalysts used for the FT process can be combined with acidic zeolites, for example in physical mixtures or by the dispersion of Co on zeolite. The purpose of this is to alter the distribution of FT products by the hydrocracking and isomerisation as soon as the products are formed (Rohde et al., 2005b). He et al. (2005) prepared a catalyst in the form of a capsule by coating a HZSM5 membrane on a preshaped $\mathrm{Co} / \mathrm{SiO}_{2}$ catalyst pellet. The capsule catalyst with HZSM5 membrane displayed brilliant selectivity for light hydrocarbon synthesis, particularly for isoparaffin synthesis from syngas $\left(\mathrm{CO}+\mathrm{H}_{2}\right)$. Long-chain hydrocarbon production was totally repressed by the zeolite membrane. The adjustment of membrane and core catalyst significantly enhanced the catalytic properties of these novel types of capsule catalysts.

\section{Conclusions}

The various applications of membrane reactors in biofuels, hydrogen and the FT process, have been presented in this work. Membrane reactors offer promising opportunities for process intensification to improve the alternative fuel production processes. They offer the combination of reaction and separation in to one single unit, and so eliminating the need for additional separation and recycling units. As a result, the fuel production process becomes less energy intensive which makes it greener and environmentally sustainable, as well as reducing capital costs. Furthermore, membrane reactors can enhance conversion and selectivity, reduce mass transfer limitations and have a greater thermal stability when compared to the conventional reactors. Membrane reactors have been mainly applied to homogeneous catalytic transesterification and heterogeneous catalytic transesterification to produce biodiesel. Membrane technology can be applied to this process based on the separation of oil droplet size, and based on catalytic membranes. It has also been found that membranes can be incorporated 
with catalysts, or by using a catalytically inert membrane for the biodiesel production process. The production of biodiesel by utilising a catalytically inert membrane needs further purification because the permeate stream comprises of catalysts, glycerol, methanol and FAME. Therefore, the membranes with the incorporated catalyst are more desirable for this process as less separation and purification is required. Recent advances for the hydrogen production process highlight the use of packed bed membrane reactors, fluidised bed membrane reactors, membrane microreactors and membrane bioreactors. Due to the fact that fluidised membrane reactors are superior to the packed bed membrane configuration, this type of reactor is most likely to be applied in industry as well as the membrane microreactors. The concept of distributed feeding, water removal, forced-through flow membrane and encapsulated catalyst have all been applied to membrane technology for the FT process. The application of forced-through flow membrane is capable for small/medium scale FT reactors. The large reactor capacities, novel concepts for heat removal and a well defined and fixed reaction zone ensure a safe and economically feasible process. The membrane reactors discussed in this paper can be applied to methane reforming and bio-ethanol reforming on a large commercial scale. Future applications of membrane reactors could include thermo-chemical treatment, such as pyrolysis of biomass and plastic waste. It can be incorporated to compliment the processing of plastic waste and biomass. On the other hand, membrane technology can also be applied to obtain higher quality distillates and fuel products from solid waste. This could be achieved by incorporating the technology downstream of processes aimed at producing gasoline, gas-oil or heavy oil from solid waste thermolysis. In addition, more research could be performed to analyse the effects of fouling and stability of the membranes, for the production of renewable fuels. The production and development of novel membrane materials, and reactor configurations, can potentially result in improvements in reactor productivity and the economics of the renewable fuel production process. Furthermore, optimization framework studies that incorporate membrane reactor technologies are very scant. Such work can be conducted to help understand the overall yield and process intensification strategies that could take place on industrial scale. Such mathematical platforms can also aid in conducting economic analysis that will render membrane technology more viable for the commercial market.

\section{References}

Abbaszaadeh A, Ghobadian B, Omidkhah MR, Najafi G (2012) Current biodiesel production technologies: a comparative review. Energy Conversion and Management 63:138-148

Aca-Aca G, Loría-Bastarrachea MI, Ruiz-Treviño FA, Aguilar-Vega M (2018) Transesterification of soybean oil by PAAc catalytic membrane: Sorption properties and reactive performance for biodiesel production. Renewable energy 116:250-257 
Aransiola E, Ojumu T, Oyekola O, Madzimbamuto T, Ikhu-Omoregbe D (2014) A review of current technology for biodiesel production: State of the art. Biomass and bioenergy 61:276-297

Atadashi I, Aroua M, Aziz AA (2011) Biodiesel separation and purification: a review. Renewable Energy 36 (2):437-443

Balthasar W (1984) Hydrogen production and technology: today, tomorrow and beyond. International Journal of Hydrogen Energy 9 (8):649-668

Baroutian S, Aroua MK, Raman AAA, Sulaiman NM (2011) A packed bed membrane reactor for production of biodiesel using activated carbon supported catalyst. Bioresource technology 102 (2):1095-1102

Baroutian S, Aroua MK, Raman AAA, Sulaiman NMN (2010) Methanol recovery during transesterification of palm oil in a $\mathrm{TiO} 2 / \mathrm{A} 12 \mathrm{O} 3$ membrane reactor: experimental study and neural network modeling. Separation and purification Technology 76 (1):58-63

Barreto RA (2018) Fossil fuels, alternative energy and economic growth. Economic Modelling 75: 196220.

Basile A, Parmaliana A, Tosti S, Iulianelli A, Gallucci F, Espro C, Spooren J (2008) Hydrogen production by methanol steam reforming carried out in membrane reactor on $\mathrm{Cu} / \mathrm{Zn} / \mathrm{Mg}$-based catalyst. Catalysis Today 137 (1):17-22

Bing W, Wei M (2019) Recent advances for solid basic catalysts: Structure design and catalytic performance, Journal of Solid State Chemistry, 269: 184-194.

Bradford MC, Te M, Pollack A (2005) Monolith loop catalytic membrane reactor for Fischer-Tropsch synthesis. Applied Catalysis A: General 283 (1-2):39-46

Buonomenna M, Choi S, Drioli E (2010) Catalysis in polymeric membrane reactors: the membrane role. Asia Pacific Journal of Chemical Engineering 5 (1):26-34

Buxbaum, R. E. (2002). U.S. Patent No. 6,461,408. Washington, DC: U.S. Patent and Trademark Office.

Cannilla C, Bonura G, Costa F, Frusteri F (2018) Biofuels production by esterification of oleic acid with ethanol using a membrane assisted reactor in vapour permeation configuration. Applied Catalysis A: General, 566: 121-129.

Cao P, Dubé MA, Tremblay AY (2008a) High-purity fatty acid methyl ester production from canola, soybean, palm, and yellow grease lipids by means of a membrane reactor. Biomass and Bioenergy 32 (11):1028-1036

Cao P, Dubé MA, Tremblay AY (2008b) Methanol recycling in the production of biodiesel in a membrane reactor. Fuel 87 (6):825-833 
Cao P, Tremblay AY, Dubé MA, Morse K (2007) Effect of membrane pore size on the performance of a membrane reactor for biodiesel production. Industrial \& engineering chemistry research 46 (1):52-58

Cerveró JM, Coca J, Luque S (2008) Production of biodiesel from vegetable oils. Grasas y aceites 59 (1):76-83

Chen H, Peng B, Wang D, Wang J (2007) Biodiesel production by the transesterification of cottonseed oil by solid acid catalysts. Frontiers of Chemical Engineering in China 1 (1):11-15

Chen HL, Lee HM, Chen SH, Chao Y, Chang MB (2008) Review of plasma catalysis on hydrocarbon reforming for hydrogen production - interaction, integration, and prospects. Applied Catalysis B: Environmental 85 (1-2):1-9

Constantinou A, Ghiotto F, Lam KF, Gavriilidis A (2014) Stripping of acetone from water with microfabricated and membrane gas-liquid contactors. Analyst 139 (1):266-272

Dalai A, Kulkarni M, Meher L Biodiesel productions from vegetable oils using heterogeneous catalysts and their applications as lubricity additives. In: EIC Climate Change Technology, 2006 IEEE, 2006. IEEE, pp 1-8

Das D, Veziroğlu TN (2001) Hydrogen production by biological processes: a survey of literature. International journal of hydrogen energy 26 (1):13-28

Demirbaş A (2002) Hydrogen production from biomass by the gasification process. Energy Sources 24 (1):59-68

DeRoussel P, Khakhar D, Ottino J (2001) Mixing of viscous immiscible liquids. Part 2: Overemulsification —interpretation and use. Chemical engineering science 56 (19):5531-5537

Di Serio M, Cozzolino M, Tesser R, Patrono P, Pinzari F, Bonelli B, Santacesaria E (2007) Vanadyl phosphate catalysts in biodiesel production. Applied Catalysis A: General 320:1-7

Di Serio M, Ledda M, Cozzolino M, Minutillo G, Tesser R, Santacesaria E (2006) Transesterification of soybean oil to biodiesel by using heterogeneous basic catalysts. Industrial \& Engineering Chemistry Research 45 (9):3009-3014

Dubé M, Tremblay A, Liu J (2007) Biodiesel production using a membrane reactor. Bioresource technology 98 (3):639-647

Edrisi SA, Abhilash PC (2016) Exploring marginal and degraded lands for biomass and bioenergy production: An Indian scenario, Renewable and Sustainable Energy Reviews, 54: 1537-1551.

Enweremadu C, Mbarawa M (2009) Technical aspects of production and analysis of biodiesel from used cooking oil—A review. Renewable and sustainable energy reviews 13 (9):2205-2224

Ersöz A (2008) Investigation of hydrocarbon reforming processes for micro-cogeneration systems. international journal of hydrogen energy 33 (23):7084-7094 
Espinoza R, Du Toit E, Santamaria J, Menendez M, Coronas J, Irusta S (2000) Use of membranes in Fischer-Tropsch reactors. In: Studies in Surface Science and Catalysis, vol 130. Elsevier, pp 389-394

Fremaux S, Beheshti S-M, Ghassemi H, Shahsavan-Markadeh R (2015) An experimental study on hydrogen-rich gas production via steam gasification of biomass in a research-scale fluidized bed. Energy Conversion and Management 91:427-432

Furuta S, Matsuhashi H, Arata K (2004) Biodiesel fuel production with solid superacid catalysis in fixed bed reactor under atmospheric pressure. Catalysis communications 5 (12):721-723

Gallucci F, De Falco M, Tosti S, Marrelli L, Basile A (2008) Co-current and counter-current configurations for ethanol steam reforming in a dense $\mathrm{Pd}-\mathrm{Ag}$ membrane reactor. International journal of hydrogen energy 33 (21):6165-6171

Gallucci F, Fernandez E, Corengia P, van Sint Annaland M (2013) Recent advances on membranes and membrane reactors for hydrogen production. Chemical Engineering Science 92:40-66

Goff MJ, Bauer NS, Lopes S, Sutterlin WR, Suppes GJ (2004) Acid-catalyzed alcoholysis of soybean oil. Journal of the American Oil Chemists' Society 81 (4):415-420

Guan H-M, Chung T-S, Huang Z, Chng ML, Kulprathipanja S (2006) Poly (vinyl alcohol) multilayer mixed matrix membranes for the dehydration of ethanol-water mixture. Journal of Membrane Science 268 (2):113-122

Guerreiro L, Castanheiro J, Fonseca I, Martin-Aranda R, Ramos A, Vital J (2006) Transesterification of soybean oil over sulfonic acid functionalised polymeric membranes. Catalysis Today 118 (1-2):166-171

Guerreiro L, Pereira P, Fonseca I, Martin-Aranda R, Ramos A, Dias J, Oliveira R, Vital J (2010) PVA embedded hydrotalcite membranes as basic catalysts for biodiesel synthesis by soybean oil methanolysis. Catalysis Today 156 (3-4):191-197

Guettel R, Kunz U, Turek T (2008) Reactors for Fischer- Tropsch Synthesis. Chemical Engineering \& Technology: Industrial Chemistry- Plant Equipment- Process Engineering- Biotechnology 31 (5):746-754

Gutiérrez-Antonio C, Ornelas MLS, Gómez-Castro FI, Hernández S, (2018) Intensification of the hydrotreating process to produce renewable aviation fuel through reactive distillation. Chemical Engineering and Processing - Process Intensification 124: 122-130.

Hafeez S, Manos G, Al-Salem SM, Aristodemou E, Constantinou A (2018) Liquid fuel synthesis in microreactors. Reaction Chemistry \& Engineering 3 (4):414-432. doi:10.1039/C8RE00040A

He J, Yoneyama Y, Xu B, Nishiyama N, Tsubaki N (2005) Designing a capsule catalyst and its application for direct synthesis of middle isoparaffins. Langmuir 21 (5):1699-1702

Holladay JD, Hu J, King DL, Wang Y (2009) An overview of hydrogen production technologies. Catalysis today 139 (4):244-260 
Jalan R, Srivastava V (1999) Studies on pyrolysis of a single biomass cylindrical pellet — kinetic and heat transfer effects. Energy Conversion and Management 40 (5):467-494

Jitputti J, Kitiyanan B, Rangsunvigit P, Bunyakiat K, Attanatho L, Jenvanitpanjakul P (2006) Transesterification of crude palm kernel oil and crude coconut oil by different solid catalysts. Chemical Engineering Journal 116 (1):61-66

Kampa M, Castanas E (2008) Human health effects of air pollution. Environmental pollution 151 (2):362-367

Keskin A, Gürü M, Altiparmak D, Aydin K (2008) Using of cotton oil soapstock biodiesel-diesel fuel blends as an alternative diesel fuel. Renewable Energy 33 (4):553-557

Khassin AA, Sipatrov AG, Chermashetseva GK, Yurieva TM, Parmon VN (2005) Fischer-Tropsch synthesis using plug-through contactor membranes based on permeable composite monoliths. Selectivity control by porous structure parameters and membrane geometry. Topics in catalysis $32(1-2): 39-46$

Kiss AA (2009) Novel process for biodiesel by reactive absorption. Separation and Purification Technology 69 (3):280-287

Kiss FE, Jovanović M, Bošković GC (2010) Economic and ecological aspects of biodiesel production over homogeneous and heterogeneous catalysts. Fuel Processing Technology 91 (10):13161320

Kleinert A, Feldhoff A, Schiestel T, Caro J (2006) Novel hollow fibre membrane reactor for the partial oxidation of methane. Catalysis today 118 (1-2):44-51

Knothe G, Krahl J, Van Gerpen J (2005) The biodiesel handbook. 2005. Champaign, IL, USA

Kouzu M, Hidaka J-s (2012) Transesterification of vegetable oil into biodiesel catalyzed by CaO: a review. Fuel 93:1-12

Licht F, Agra C (2007) World biodiesel markets: The outlook to 2010. Agra Informa Ltd, Kent, United Kingdom 200

Lipnizki F, Field RW, Ten P-K (1999) Pervaporation-based hybrid process: a review of process design, applications and economics. Journal of Membrane Science 153 (2):183-210

Liu X, He H, Wang Y, Zhu S, Piao X (2008) Transesterification of soybean oil to biodiesel using CaO as a solid base catalyst. Fuel 87 (2):216-221

Lotero E, Goodwin JG, Bruce DA, Suwannakarn K, Liu Y, Lopez DE (2006) The catalysis of biodiesel synthesis. catalysis 19 (1):41-83

Lu G, Da Costa JD, Duke M, Giessler S, Socolow R, Williams R, Kreutz T (2007) Inorganic membranes for hydrogen production and purification: a critical review and perspective. Journal of colloid and interface science 314 (2):589-603

Ma F, Hanna MA (1999) Biodiesel production: a review. Bioresource technology 70 (1):1-15

Maneerung T, Hidajat K, Kawi S (2016) Triple-layer catalytic hollow fiber membrane reactor for hydrogen production. Journal of Membrane Science 514:1-14 
Marbán G, Valdés-Solís T (2007) Towards the hydrogen economy? International Journal of Hydrogen Energy 32 (12):1625-1637

Marcano JGS, Tsotsis TT (2002) Catalytic membranes and membrane reactors. Wiley-VCH Verlag $\mathrm{GmbH}$,

Meher LC, Kulkarni MG, Dalai AK, Naik SN (2006) Transesterification of karanja (Pongamia pinnata) oil by solid basic catalysts. European Journal of Lipid Science and Technology 108 (5):389397

Mejdell A, Jøndahl M, Peters T, Bredesen R, Venvik H (2009a) Effects of CO and CO2 on hydrogen permeation through a $3 \mu \mathrm{m} \mathrm{Pd} / \mathrm{Ag} 23 \mathrm{wt} . \%$ membrane employed in a microchannel membrane configuration. Separation and Purification Technology 68 (2):178-184

Mejdell A, Jøndahl M, Peters T, Bredesen R, Venvik H (2009b) Experimental investigation of a microchannel membrane configuration with a $1.4 \mu \mathrm{m} \mathrm{Pd} / \mathrm{Ag} 23$ wt.\% membrane-effects of flow and pressure. Journal of Membrane Science 327 (1-2):6-10

Mejdell A, Peters T, Stange M, Venvik H, Bredesen R (2009c) Performance and application of thin Pdalloy hydrogen separation membranes in different configurations. Journal of the Taiwan Institute of Chemical Engineers 40 (3):253-259

Mueller U, Schubert M, Yaghi O, Ertl G, Knözinger H, Schüth F, Weitkamp J (2008) Handbook of Heterogeneous Catalysis. Wiley-VCH, Weinheim 1:247-262

Muradov N (1993) How to produce hydrogen from fossil fuels without CO2 emission. International Journal of Hydrogen Energy 18 (3):211-215

Ni M, Leung DY, Leung MK, Sumathy K (2006) An overview of hydrogen production from biomass. Fuel processing technology 87 (5):461-472

Nikolaidis P, Poullikkas A (2017) A comparative overview of hydrogen production processes. Renewable and sustainable energy reviews 67:597-611

Pal P, Kumar R, Ghosh AK (2018) Analysis of process intensification and performance assessment for fermentative continuous production of bioethanol in a multi-staged membrane-integrated bioreactor system, Energy Conversion and Management, 171: 371-383.

Patil PD, Deng S (2009) Optimization of biodiesel production from edible and non-edible vegetable oils. Fuel 88 (7):1302-1306

Rahimpour M (2015) Membrane reactors for biodiesel production and processing. In: Membrane Reactors for Energy Applications and Basic Chemical Production. Elsevier, pp 289-312

Rahimpour M, Bayat M (2011) Production of ultrapure hydrogen via utilizing fluidization concept from coupling of methanol and benzene synthesis in a hydrogen-permselective membrane reactor. international journal of hydrogen energy 36 (11):6616-6627 
Ramadhas A, Jayaraj S, Muraleedharan C (2004) Use of vegetable oils as IC engine fuels-a review. Renewable energy 29 (5):727-742

Rohde MP, Unruh D, Schaub G (2005a) Membrane application in Fischer- Tropsch synthesis to enhance CO2 hydrogenation. Industrial \& engineering chemistry research 44 (25):9653-9658

Rohde MP, Unruh D, Schaub G (2005b) Membrane application in Fischer-Tropsch synthesis reactorsOverview of concepts. Catalysis today 106 (1-4):143-148

Rostrup-Nielsen J (2003) Encyclopedia of Catalysis. vol,

Saleh J, Tremblay AY, Dubé MA (2010) Glycerol removal from biodiesel using membrane separation technology. Fuel 89 (9):2260-2266

Sarkar B, Sridhar S, Saravanan K, Kale V (2010) Preparation of fatty acid methyl ester through temperature gradient driven pervaporation process. Chemical Engineering Journal 162 (2):609615

Shao P, Huang R (2007) Polymeric membrane pervaporation. Journal of membrane science 287 (2):162-179

Sharma Y, Singh B, Upadhyay S (2009) Response to the comments on "Advancements in development and characterization of biodiesel: A review". Sharma YC, Singh B, Upadhyay SN. Fuel 2008; 87: 2355-73 by Clifford Jones. Fuel 4 (88):768-769

Shi W, He B, Ding J, Li J, Yan F, Liang X (2010) Preparation and characterization of the organicinorganic hybrid membrane for biodiesel production. Bioresource technology 101 (5):15011505

Shuit SH, Ong YT, Lee KT, Subhash B, Tan SH (2012) Membrane technology as a promising alternative in biodiesel production: a review. Biotechnology advances 30 (6):1364-1380

Singh AK, Fernando SD (2007) Reaction kinetics of soybean oil transesterification using heterogeneous metal oxide catalysts. Chemical Engineering \& Technology: Industrial Chemistry- Plant Equipment- Process Engineering- Biotechnology 30 (12):1716-1720

Spallina V, Matturro G, Ruocco C, Meloni E, Palma V, Fernandez E, Melendez J, Tanaka AP, Sole JV, van Sint Annaland M (2018) Direct route from ethanol to pure hydrogen through autothermal reforming in a membrane reactor: Experimental demonstration, reactor modelling and design. Energy 143:666-681

Stankiewicz A (2003) Reactive separations for process intensification: an industrial perspective. Chemical Engineering and Processing: Process Intensification 42 (3):137-144

Steinberg M, Cheng HC (1989) Modern and prospective technologies for hydrogen production from fossil fuels. International Journal of Hydrogen Energy 14 (11):797-820

Tian Y, Demirel SE, Hasan MMF, Pistikopoulos EN (2018) An overview of process systems engineering approaches for process intensification: State of the art. Chemical Engineering and Processing - Process Intensification, 133: 160-210. 
Tosti S, Basile A, Bettinali L, Borgognoni F, Gallucci F, Rizzello C (2008) Design and process study of Pd membrane reactors. International Journal of Hydrogen Energy 33 (19):5098-5105

Van Der Laan GP, Beenackers A (1999) Kinetics and selectivity of the Fischer-Tropsch synthesis: a literature review. Catalysis Reviews 41 (3-4):255-318

Wang L, Yang J (2007) Transesterification of soybean oil with nano-MgO or not in supercritical and subcritical methanol. Fuel 86 (3):328-333

Wang Y, Wang X, Liu Y, Ou S, Tan Y, Tang S (2009) Refining of biodiesel by ceramic membrane separation. Fuel Processing Technology 90 (3):422-427

Wen M, Mori K, Kuwahara Y, An T, Yamashita H (2018) Design and architecture of metal organic frameworks for visible light enhanced hydrogen production, Applied Catalysis B: Environmental, 218: 555-569.

Wilhelm D, Simbeck D, Karp A, Dickenson R (2001) Syngas production for gas-to-liquids applications: technologies, issues and outlook. Fuel processing technology 71 (1-3):139-148

Yusuf N, Kamarudin SK, Yaakub Z (2011) Overview on the current trends in biodiesel production. Energy conversion and management 52 (7):2741-2751

Zhang G, Jin W, Xu N (2018) Design and Fabrication of Ceramic Catalytic Membrane Reactors for Green Chemical Engineering Applications. Engineering, 4(6): 848-860.

Zhu M, He B, Shi W, Feng Y, Ding J, Li J, Zeng F (2010) Preparation and characterization of PSSA/PVA catalytic membrane for biodiesel production. Fuel 89 (9):2299-2304

Zhu W, Gora L, Van den Berg A, Kapteijn F, Jansen J, Moulijn J (2005) Water vapour separation from permanent gases by a zeolite-4A membrane. Journal of membrane science 253 (1-2):57-66 